\title{
Migrantes e migrações: entre a história e a literatura
}

\author{
Luciene Lemos de Campos* \\ Luciano Rodrigues ${ }^{* *}$
}

Migrantes são indivíduos que por necessidade de sobrevivência, imposições — políticas, econômicas, sociais e culturais - ou por opção, convivem com uma realidade sociocultural diversa da sua. $\mathrm{O}$ que os caracteriza é o deslocamento no espaço: deixam um território para se fixarem - ou não - em um novo. Esse fluxo populacional contém significados além do simples deslocamento. Os migrantes, na história da humanidade, exerceram, e exercem papel de destaque na formação sócio-cultural de diversas etnias. Neste trabalho, utilizando-nos do método de pesquisa bibliográfica, fazemos estudo interdisciplinar na interface da História com a Literatura. Nosso corpus contempla poesias de Manoel de Barros, narrativas de outros literatos e referencial em obras de Abdelmalek Sayd, Pierre Bordieu, Eric Hobsbawn e Stuart Hall. A partir da História e da ficção, interligamos o factual com o ficcional.

Palavras-chave: História; Fronteira; Literatura Brasileira

Migrants are individuals who by necessity of survival, taxes - political, economic, social

\section{Introdução}

om o surgimento do homem na África e a partir do momento em que teve conhecimento de vários aspectos para interferir na natureza, criaram-se condições para se deslocar para várias regiões da Terra. Nesse sentido, os movimentos populacionais são frequentes e comuns na história da humanidade, sendo responsáveis pelas diversidades étnicas dos elementos culturais e de identificação ${ }^{1}$.

Assim, na Antiguidade, a formação da Mesopotâmia deveu-se, entre vários aspectos, à migração e ao povoamento pelos sumérios, assírios, ba-

\footnotetext{
${ }^{*}$ Mestre em Estudos Fronteiriços. Professora de língua Portuguesa e Literatura - SED/MS. E-mail: lucienelemos10@yahoo.com.br

** Mestre em Estudos Fronteiriços. Colaborador do Laboratório de Estudos Fronteiriços/CPAN/ UFMS. E-mail: luciano01rodrigues@yahoo.com.br

${ }^{1}$ GONÇALVES, Ana Teresa M., ROCHA, Leandro Mendes. Identidades e etnicidades conceitos e preceitos. In: SILVA, Gilvan Ventura da; NADER, Maria Beatriz; FRANCO, Sebastião Pimentel (Org.). As identidades no tempo: ensaio de gênero, etnia e religião. Vitória, ES: EDUFES, 2006, p. 11.
} 
and cultural - or by choice, live with a diverse socio-cultural reality of its own. What characterizes them is the displacement in space: no longer a territory to settle - or not - into a new one. This population flow has meanings beyond the simple displacement. Migrants in the history of mankind, engaged, and engaged role in the socio-cultural training ethnically diverse. In this work, using the method of literature search, we do inter- disciplinary study on the interface between History and Literature. Our corpus includes poems by Manoel de Barros, narratives and other literary references in works by $\mathrm{Ab}$ delmalek Sayd, Pierre Bourdieu, Eric Hobsbawm and Stuart Hall. From history and fiction, we linked the factual with the fictional.

Key words: History, Frontier, Brazilian Literature

bilônicos e arcádios. Nesse sentido, a formação da civilização grega advém de movimentos migratórios de povos como Jônios, Eólios, Aqueus e Dóricos, os quais colaboraram para a formação de aspectos sociais e culturais dessa civilização. Da mesma forma, a origem histórica de Roma está associada a elementos estrangeiros como latinos, sabinos, etruscos e gregos, povos que influenciaram na cultura e sociedade romana. Assim, a invasão dos povos bárbaros em Roma constituiu novas formas sociais que predominaram na Idade Média, como a economia agropastoril, bem como o comitatus e o beneficium.

Com a formação do Estado Moderno no século XV, através da unificação das monarquias, o homem passa a ter a consciência e o sentimento de pertencer a uma Nação ${ }^{2}$. As guerras foram elementos essenciais para a construção dos Estados Nacionais; a França, por exemplo, na Guerra dos Cem anos (1334-1453), formou um exército único e fortaleceu o sentimento nacionalista francês. Com o fortalecimento do sentimento de pertença de um Estado ou Nação, a visão sobre os migrantes começa, cada vez mais, a se tornar exótica ${ }^{3}$.

Evidentemente, não podemos concluir que ao longo desses séculos, o processo de migração tenha sido idêntico, posto que o século XIX, por exemplo, tem outras peculiaridades que, para este estudo, não nos interessa aprofundar.

\footnotetext{
${ }^{2}$ MARQUES, Adhemar, BERUTTI, Flávio C., FARIA, Ricardo de Moura. História através de textos. São Paulo: Contexto, 1989, p. 13.

${ }^{3}$ Conforme homologa Marco Aurélio Machado de Oliveira em seu artigo, Os imigrantes e as fronteiras: armadilhas interpretativas, a palavra exótico em seu sentido original é tratada como, fora do lugar comum da visão, estranho. (grifo nosso). In: COSTA, Edgar Aparecido, OLIVEIRA, Marco Aurélio de (Orgs.). Seminário de estudos fronteiriços. Campo Grande: UFMS, 2009.
} 
Nos dias correntes, as migrações se processam de forma inversa quanto aos processos burocráticos: migrantes - principalmente de países considerados de terceiro mundo - partem para países europeus de economias mais estáveis, almejando novos contornos sociais e financeiros, e em muitos casos realizam atividades laborais consideradas marginais pelas sociedades receptoras: garçons, diaristas, jardineiros, entre outras ${ }^{4}$. Entretanto, retornam aos seus países de origem.

De acordo com o relatório do Banco Mundial (1995), mais de 125 milhões de pessoas são migrantes no mundo. Para Hobsbawn ${ }^{5}$, dentre os mais diversos motivos que levam o indivíduo ao processo migratório são as guerras, conflitos internos e perseguições políticas. Esse processo se justifica, sobretudo pelas condições sociais e econômicas do indivíduo em seu país de origem. Cabe-nos acrescentar que questões de ordens sociais, morais, religiosas e familiares também fazem parte desse caminho.

Assim, conforme Silva': "Quem migra leva consigo sonhos de uma vida melhor para si e suas famílias, de obter sucesso econômico rápido e de regressar vitorioso, o quanto antes, à sua terra natal, pois o retorno é, segundo Sayad (2000), um elemento constitutivo da condição do imigrante."

A decisão de migrar parece sempre ancorada em ideias positivas que são construídas sobre o lugar de destino, as quais são veiculadas, em geral, pela imprensa, ou ainda pelos agenciadores de imigrantes no local de partida, estimulando o imaginário dos migrantes. Em outras palavras, o imaginário é o modo pelo qual os historiadores lidam com certa dimensão cultural da história, para dar conta de idéias e representações que, traduzindo-se em imagens, não são explicáveis em termos de uma história événementielle ou conjuntural porque remetem a conteúdos culturais de outra natureza.

\footnotetext{
${ }^{4}$ NETO, H. P. A imagem da imprensa sobre a emigração brasileira. Estudos Avançados, n. 20, São Paulo, 2006, p. 25.

${ }^{5}$ HOBSBAWN, Eric J. A era do capital: 1848 - 1875. Trad. Luciano Costa Neto. $2^{\mathrm{a}}$. Ed. Rio de Janeiro: Ed. Paz e Terra, 1979.

${ }^{6}$ SILVA, Antonio da S. Bolivianos em São Paulo: entre o sonho e a realidade. In: Estudos avançados, v. 20, n. 57, São Paulo, maio/agosto, 2006, p. 2.
} 
Em consonância com a afirmação de Bordieu?: "O ato da magia social que consiste em tentar trazer à existência a coisa nomeada pode resultar se aquele que o realiza for capaz de fazer reconhecer à sua palavra o poder que ela se arroga por uma usurpação provisória ou definitiva, o de impor uma nova visão a uma nova divisão do mundo social [...]"

Ressaltamos que o fenômeno migratório não é simplesmente processo de deslocamento populacional de um local mais pobre para um mais rico. Em torno do migrante está contida uma áurea de dor, alegria, saudade, esperanças e ilusões. Lembranças do que deixou e sonhos do que pretende conquistar. Ao elaborar constantemente suas expectativas por dias melhores, o migrante leva e traz consigo a mala e a alma. Nesse sentido, o fenômeno migratório é geralmente marcado por tensões e estranhamentos tanto do imigrante que estará submetido a novas ordens e desordens que se difere de seu local de origem para o local receptor, que tende a vê-los através de estereótipos já construídos ${ }^{8}$.

Em sintonia, faz sentido destacar que: "É na ordem das humanidades que se estabelece o imigrante, e não ao contrário. Suas trajetórias pessoais, condutoras de dramas, tragédias e sucessos, são expressões daquilo que não está, necessariamente, materializado." $"$.

Com efeito, estudos sobre movimentos populacionais revelam características e aspectos culturais, econômicos, sociais e religiosos que somente podem ser compreendidos melhor pela ótica migratória. Dessa maneira, os fluxos migratórios estão associados à formação e à edificação de várias sociedades. O migrante convive com o confronto e a constante tentativa de construção/reconstrução ou constituição de suas representações e identidades, perante os habitantes locais. Nesse contexto social, delicado, a construção da identidade de cada indivíduo, situa-se na representação que ele dá de si mesmo e da credibilidade atribuída ou recusada pelos outros a essa representação. Logo, a identidade não é singular. Em um sentido mais amplo, poder-se-ia dizer que o migrante torna-se "um outro" ampliado.

${ }^{7}$ BORDIEU, Pierre. O poder simbólico. Trad. Fernando Tomáz. Rio de Janeiro: Ed. Bertrand Brasil S/A, 1989, p. 116.

${ }^{8}$ SILVA, Antonio da S. Op. cit.

${ }^{9}$ OLIVEIRA, Marco A. M. Os imigrantes..., op. cit. 


\section{Migrantes no Brasil: problematizações}

No Brasil, o movimento de migração não foi diferente. Os migrantes portugueses que aqui chegaram, desenvolveram suas práticas culturais, religiosas e sociais. Nesse sentido, os migrantes africanos trazidos pelos portugueses, como mão-de-obra escrava, contribuíram sobremaneira para a formação cultural brasileira. Assim, é importante entendermos alguns aspectos da política migratória brasileira e que esta, em seu período imperial, esteve associada aos interesses dos grupos que detinham o poder.

Em 1824, iniciaram-se tentativas de dinamizar fluxos migratórios de europeus para o Brasil. Nesse caso, o marco principal, a colônia de São Leopoldo, no Rio Grande do Sul, constituiu-se como primeira colonização de migrantes nãolusos. Mister que tal política foi bastante criticada pelos latifundiários e, em 15 de novembro de 1830, foi sancionada uma lei que proibia gastos públicos com colonização de grupos estrangeiros ${ }^{10}$. Nesse sentido, mesmo com a implantação de várias leis cujo intuito era incentivar a migração estrangeira como: lei número 514, de 28 de outubro de 1848, que concedia terras devolutas às províncias; a lei número 581, de 4 de setembro de 1850 , que proibia o tráfico e a entrada de escravos no Brasil, incentivando e estimulando a iniciativa privada a investir em recursos para migração estrangeira; Repartição Geral das Terras Públicas propiciando, assim, o ingresso de estrangeiros para o Brasil.

Apesar de todas essas tentativas, o índice de migrantes estrangeiros no território brasileiro continuava insatisfatório. Já nas últimas décadas do século XIX, os números de estrangeiros para o Brasil começam a aumentar - com destaque à migração de italianos. $\mathrm{O}$ início do século $\mathrm{XX}$ corresponde ao período de grande fluxo migratório estrangeiro para o Brasil.

Assim, nas palavras de Luiza Horn Lotti ${ }^{11}$

\footnotetext{
${ }^{10}$ LOTTI, Horn Luiza. A política imigratória brasileira e sua legislação - 1822 - 1914. In: SILVA, Gilvan Ventura da; NADER, Maria Beatriz; FRANCO, Sebastião Pimentel (Orgs.). As identidades no tempo: ensaio de gênero, etnia e religião. Vitória: Ed. EDUFES, 2006, p. 249.
}

${ }^{11}$ Idem, p. 257. 
a corrente migratória ganhou novo impulso, atingindo altos níveis em 1911 - 13 para logo depois, declinar em decorrência da guerra que irrompera na Europa, (...) Em 1913, entraram no Brasil 190.333 imigrantes. No ano seguinte este número caiu para 79.232. E, em 1915, para 30.333 imigrantes (...). Em linhas gerais, pode-se verificar que, no Brasil, a colonização oficial antecedeu à particular, caracterizando-se como um projeto intervencionista na sociedade (...0.

É pertinente acrescentar, neste estudo, dados do Instituto Brasileiro de Geográfica e Estatística (IBGE) sobre o deslocamento de correntes migratórias de diversos continentes do mundo para o Brasil.

Deslocamento populacional para o Brasil/GERAL - 1940 - 1991

\begin{tabular}{|l|c|c|c|c|c|c|}
\hline \multicolumn{1}{|c|}{ CONTINENTE } & $\mathbf{1 9 4 0}$ & $\mathbf{1 9 5 0}$ & $\mathbf{1 9 6 0}$ & $\mathbf{1 9 7 0}$ & $\mathbf{1 9 8 0}$ & $\mathbf{1 9 9 1}$ \\
\hline AMÉRICA DO SUL & 17.216 & - & 15.673 & 16.042 & 6.879 & 5.565 \\
\hline EUROPA & 2.725 & - & 2.644 & 2.474 & 1.745 & 1.221 \\
\hline ÁSIA & 2.221 & - & 4.526 & 4.301 & 2.625 & 1.529 \\
\hline ÁFRICA & 10 & - & 11 & 21 & 49 & 82 \\
\hline OCEANIA & 01 & - & 07 & 04 & 04 & - \\
\hline
\end{tabular}

Fontes: Dados Recenseamento Geral do Brasil - Mato Grosso, pag.10, $\mathrm{n}^{\circ} 430$. Recenseamento Geral do Brasil, 1950. Mato Grosso, pag. 01-02, $\mathrm{n}^{\circ}$ 431. Recenseamento Censo Demográfico Mato Grosso, 1960, pag. 14, n 2.177. Censo Demográfico Mato Grosso , 1970, pag. 21, $\mathrm{n}^{\circ} 515$. Censo Demográfico Mato Grosso do Sul, 1980, pág 52, nº 523. Censo Demográfico Mato Grosso do Su,l 1991, pag. 53, nº 3302

Nesse contexto, a formação do Brasil está associada a indivíduos estrangeiros os quais trouxeram de seus países de origem - Itália, Japão, Espanha, entre outros - características sociais, religiosas, linguísticas, e culturais que muitas vezes são interpretadas de formas diversificadas e, às vezes, enraizadas pela forma do preconceito. Porém, a migração está muito além do preconceito, associada a elementos de conveniência e conduzida pelos grupos detentores do poder político-econômico.

Em 1998, o Presidente Fernando Henrique Cardoso promulgou uma anistia aos estrangeiros em situação irregular no País. Entretanto, se considerarmos os dados estatísticos daquele ano, constataremos que, ao mesmo tempo, houve redução do fluxo de imigrantes e aumento do volume de emigrantes em algumas das regiões brasileiras. 


\section{Lembra-nos Sayad ${ }^{12}$ de que}

Uma das características fundamentais do fenômeno da imigração é que fora algumas situações excepcionais, ele contribui para dissimular a si mesmo sua própria verdade. [...] a imigração condena-se a engendrar uma situação que parece destiná-la a uma dupla contradição: não se sabe mais se trata de um estado provisório que se gosta de prolongar indefinidamente ou, ao contrário, se trata de um estado mais duradouro, mas que se gosta de viver com um intenso sentimento de provisoriedade.

A política migratória imposta no Brasil sempre esteve vinculada ao que era conveniente aos grupos dominantes. A conjuntura de cada época, tanto no aspecto político quanto no econômico e no social, tem influenciado o posicionamento desses grupos frente a essa questão.

O geógrafo Rui Leandro Maia afirma que a migração implica fluxos de indivíduos ou grupos que se deslocam entre duas sociedades. Logo, a migração é definida como um processo criador de redes na medida em que os contatos entre o local de origem e destino se tornem mais densos.

Nos dizeres de Maia ${ }^{13}$, “[...] A noção de redes de relações sociais remetenos para novas leituras sobre os percursos migratórios: permite superar as analises migratórias feitas em exclusivo a partir de um dos espaços a que os migrantes se encontram ligados, o de origem e de acolhimento."

Dessa maneira, parece-nos de singular pertinência, quando se buscam respostas para os fenômenos migratórios que têm ocorrido no País, analisar tais fenômenos a partir de olhares de variados campos do conhecimento.

\subsection{Migrantes:}

\section{a literatura na interface com a história}

O sentido da migração que pretendemos explorar transcende o simples deslocamento entre países, visto que esses deslocamentos não são operados ape-

\footnotetext{
12 SAYAD, Abdelmalek. Imigração. São Paulo: Cia. das Letras, 1997, p. 49.

${ }^{13}$ MAIA, L. Rui. Migrações e redes de relações socais em meio urbano: um exemplo a partir do Porto. In: Revista de Demografia Histórica, XX, I, 2002, segunda época, p. 54.
} 
nas no espaço e tempo manipulados pela racionalidade factual. Não podemos desconsiderar a migração metafórica ${ }^{14}$, a dissimulação para si mesmo e para os outros quanto à origem e ao destino do ser migrante.

No espaço da ficção, o migrante parece mais atuante e visível que no espaço factual. Não raro, temos nos deparado com produções literárias nas quais percebemos expressivos traços documentais de diversos tipos de migrações.

Contextualizar o migrante a partir de nossas experiências e entendimentos, é esquecer que esse ser traz consigo um arcabouço de experiências, (in)certezas, sonhos, desejos e ilusões. Assim, nos perguntamos: quem é migrante no final do século XX e início do século XXI? Que busca? De que foge? Por que retorna? Tendo em vista tais inquietações, voltamo-nos para as considerações da estudiosa Karime Amaral Hauaji.

As razões que explicam as migrações foram - e continuam sendo — inúmeras. De acordo com Hauaji ${ }^{15}$, sob a ótica da ficção, o ensaísta quebequense Pierre Quellet, na estesia migrante, distingue quatro classes de personagens, todas ligadas a uma forma de "alteropercepção".

A primeira diz respeito ao estrangeiro, ao exilado ou ao viajante, que dá lugar ao fluxo migratório, construindo o discurso subjetivo. A segunda, aos artistas, escritores e pensadores, permite um tipo de migração metafórica, própria da experiência estética ou cognitiva. A terceira, a do louco ou demente, que nos remete à migração psicológica. Finalmente, a do excluído, marginal ou itinerante, cuja identidade é colocada em cheque pela ausência de um espaço de existência ou de um campo de pertencimento.

O migrante é o indivíduo que, por necessidade de sobrevivência ou mesmo por opção passa a conviver com uma realidade sociocultural diversa. Uma das características desse personagem é o seu deslocamento no espaço, deixa um espaço para, às vezes, se fixar em outro; várias são as razões que o levam a migrar. Assim, o migrante parece assimilar várias identidades, pois que identifica com

\footnotetext{
${ }^{14} \mathrm{Em}$ Os limites da interpretação, Eco assinala que a metáfora lida com algo que concerne à nossa experiência interior do mundo, e aos nossos processos emotivos. Cf. ECO, Umberto. Os limites da interpretação. São Paulo: Perspectiva, 1995, p. 121.

${ }^{15}$ HAUAJ, Karime Amaral. Estranho familiar: impressões do imigrante em sua relação com a terra, a cultura e a literatura. In: SANTOS, Ana Cristina dos; ALMEIDA, Claudia; BATALHA, Maria Cristina (Orgs.). Identidades fora de foco. Rio de Janeiro: Cia. das Letras, 2009, p. 42.
} 
os lugares por onde passa e dele reproduz algum costume ou comportamento. $\mathrm{O}$ migrante tende a ampliar sua identidade de origem e, portanto, a não se identificar com um único território: o "eu” acaba por escapar à vista, dando lugar a um "outro" ampliado. ${ }^{16}$

O caráter temporal e a presença limitada do migrante em determinado território, muitas vezes, depende unicamente das condições econômicas ou das condições naturais, como as secas, as enchentes entre outras, as quais podem intensificar ou reduzir o processo migratório em determinados períodos.

Osman ${ }^{17}$ proporciona-nos a seguinte reflexão:

Se é necessário rediscutir e reavaliar a importância dos estudos sobre migração, é mais necessário ainda discutir um dos pontos mais produtivos e críticos dessa análise: o tema do retorno, os estudos sobre o tema não podem mais ser negligenciados, fazendo-se necessária a compreensão da magnitude e dinâmica da migração de retorno aos países de origem, nos diferentes cenários nos quais ocorre o retorno.

Vale observar que, a partir das duas últimas décadas do século XIX e com o advento do romance social, a literatura brasileira inicia uma consciência crítica das oposições campo/cidade, imigrante/nacional. Trata-se de uma literatura que traz para a reflexão, dentre outras questões, problemas sociais, a fim de contribuir para possíveis soluções. Nesse sentido, muitas produções literárias, a partir de então, têm abordado o tema da errância, da migração. Para citarmos apenas alguns escritores: Alcântara Machado, Antônio Torres, Bernardo Carvalho, Érico Veríssimo, Graça Aranha, Graciliano Ramos, Guimarães Rosa, João Cabral de Melo Neto, Jorge Amado, José Américo de Almeida, Luiz Ruffato, Luiz Vilela, Manoel de Barros, Marcelino Freire, Milton Hatoum, Moacyr Scliar, Rachel de Queiroz, Raduan Nassar, Taunay entre outros.

A literatura brasileira oferece um número significativo de obras que, dentre diferentes possibilidades de leitura, permitem também identificar a condição do

\footnotetext{
${ }^{16}$ De acordo com Stuart Hall (2006, p. 69), a situação de migrante acaba por construir identidades híbridas. Cf. HALL, Stuart. A identidade cultural na pós-modernidade. Trad. Tomaz Tadeu da Silva, Guaracira Lopes Louro, 11ª . Ed., Rio de Janeiro: DP\&A, 2006.

${ }^{17}$ OSMAN, Samira Adel. A imigração libanesa para o Brasil e o Projeto de Retorno. In: JARDIM, Denise Fagundes, OLIVEIRA, Marco Aurélio (Orgs.). Os árabes e suas Américas. Campo Grande: UFMS, 2008, p. 164.
} 
migrante e as consequências advindas dos movimentos que conduzem essa personagem a novos caminhos: o da partida e o da chegada ou vice-versa.

Estudos recentes sobre movimentos populacionais revelam características e aspectos culturais, econômicos, sociais e religiosos, que talvez possam ser melhores compreendidos pela ótica migratória, pela subjetividade.

Da leitura que fazemos da poesia de Manoel de Barros, parece-nos, emergir um entrelaçamento de cultura, memória e sentimento de pertença no migrante barreano. Não se trata, entretanto, de um testemunho autêntico, espelhamento do que é registrado pelos historiadores. Trata-se de uma concepção subjetiva de enunciador que dá voz a um ser — ainda que inventado - e, ao mesmo tempo, busca sentido para a poesia.

Na obra O Livro das Ignorãças, há uma:

\section{EXPLICAÇÃO DESNECESSÁRIA}

Na enchente de 22, a maior de todas as enchentes do Pantanal, canoeiro Apuleio vagou três dias e três noites por cima das águas, sem comer sem dormir ele teve um delírio frásico. A estórea aconteceu que um dia, remexendo papéis na Biblioteca do Centro de Criadores da Nhecolândia, em Corumbá, dei com um pequeno Caderno de Armazém, onde se anotavam compras fiadas de arroz, feijão, fumo etc. $[\ldots]^{18}$

Nessa "Explicação", notamos que o território descrito é vital à poesia e, ao mesmo tempo, é espaço de deslocamento do outro. Não se trata aqui de evidenciar territorialidades, mas ao focalizar o entorno, a "Nhecolândia, em Corumbá"19, o poeta faz emergir identidades com as quais, com o passar do tempo, cada vez menos se identifica, visto que o tempo e os constantes deslocamentos entre o centro e a periferia transformaram-no em outro; agora, conotativamente, metamorfizado em migrante, andarilho. Por isso, o eu poético busca, nas suas Memórias Inventadas, re-encontrar o eu primevo.

E, ainda, se analisarmos a biografia de Manoel Wenceslau Leite de Barros, suas idas e vindas de Mato Grosso, Mato Grosso do Sul, Rio de Janeiro, Bolívia, Peru, Estados Unidos entre outras tantas viagens por ele realizadas, conside-

\footnotetext{
${ }^{18}$ BARROS, Manoel de. O livro das ignorãças. $10^{\mathrm{a}}$ ed. Rio de Janeiro: Record, 2001, p. 31.

${ }^{19}$ Idem.
} 
ramos possível emergirem-se estudos inovadores acerca do poeta migrante em comparação com o eu-lírico migrante. Desse modo, nos questionamos: a poesia barreana transita entre o que foi e o que não foi vivido pelo poeta?

A obra de Manoel de Barros está para aquele que não se limitou ao poder normatizador da poesia, não reduziu sua produção literária a "formas a forma "20, assim como o migrante está para o diferente, o marginalizado, aquele transgride a ordem das fronteiras, pois desestabiliza o "olhar".

Em O livro das ignorãças, eis um poema, que homologa tal raciocínio:

XIV

De 1940 a 1946 vivi em lugares decadentes onde o mato e a fome tomavam conta das casas, dos seus loucos, de suas crianças e de seus bêbados.

Ali me anonimei de árvore.

Me arrastei por beiradas de muros cariados desde Puerto Suarez, Chiquitos, Oruros e Santa Cruz de La Sierra, na Bolívia.

[...] Eu precisava de ficar pregado nas coisas vegetalmente e achar o que não procurava. ${ }^{21}$.

Verificamos, nesse poema, que, ao partir do local de origem, o eu-lírico migrante deixa suas realizações e observa lugares estranhos ao seu "olhar", de certa forma, possível na poesia, abdica-se de si mesmo, "Ali me anonimei de árvore", tornando-se um anônimo, sem nome, sem identidade. Em suma, um estranho a si mesmo.

Ao romper laços de tempo e espaço com sua terra de origem, esse migrante não se encontra em lugar nenhum, já que "precisava achar o que não procurava" 22 , torna-se, assim, um promotor de integração e de mudanças no território em que se sentir "acolhido".

$\operatorname{Sayad}^{23}$ assim se expressa quanto à noção de pertença:

\footnotetext{
${ }^{20}$ Expressão poética de Manuel Bandeira.

${ }^{21}$ BARROS, Manoel de. Op. cit., p. 101.

${ }^{22}$ Idem.

${ }^{23}$ SAYAD, Abdelmalek. O retorno: elemento constitutivo da condição do migrante. Travessia, v. 13, n. especial, jan. 2000, p. 13.
} 
ao tempo, ao espaço, ao grupo, os principais quadros que estruturam a vida social e mesmo toda vida social e mesmo toda existência individual - existir no tempo, no espaço e no interior de um grupo social (é a condição da existência política) - sempre está em causa um pertencimento nacional, um pertencimento nacionalmente definido: o pertencimento a cada um a seu tempo é um pertencimento à história nacional; o pertencimento ao espaço é um pertencimento ao território nacional; o pertencimento ao grupo dos nacionais é um pertencimento à nação e à nacionalidade que lhe são comuns.

A personagem migrante, muitas vezes recorrente no imaginário social, tem seu lugar, desde muito tempo, nas artes plásticas, na Literatura, na Antropologia, na História das civilizações entre outras áreas do conhecimento. O tema da viagem parece atrair o homem em todo tempo e espaço.

O fluxo da migração vem sendo vastamente estudado. Contudo, há poucos anos, têm se tornado objeto de pesquisas historiográficas e literárias nas academias do Brasil. A migração, assim nos parece, é um fenômeno antitético e que precisa ser esclarecido melhor. Caso contrário, tornar-se-á fruto de especulações rasas e estereotipadas.

O artigo Migração e Literatura, referenda nossa interpretação: "É entre a migração e a literatura que se esclarece e se faz pensar melhor a condição humana de nossa época e a ressonância e a importância de sua voz, "os seus sons" ( são as palavras- conceito empregadas por Leopardi em "Infinito"), que a exprimem e apresentam. A essa voz sazonal ninguém deve responder."24.

Sempre que comparamos um texto ficcional com um texto não-ficcional, emergem discussões relacionadas entre arte e vida. No âmbito dessas discussões, a literatura de ficção produzida no Brasil muito tem contribuído para diluir tais fronteiras.

Cabe-nos observar que, já na Antiguidade, surgiam discussões acerca da distinção entre Literatura e História - não será demais lembrar os ensinamentos de Aristóteles, que, no Capítulo IX da sua Arte Poética, trata da diferença que existe entre a Poesia e a História:

\footnotetext{
${ }^{24}$ GNISCI, Armando. Migração e literatura. Universidade de Roma "La Sapienza”, terad. Shirley de Souza Gomes Carreira. In: Revista Eletrônica do Instituto de Humanidades, 2003. Disponível em www.algosobre.com.br/.../migrações-populacionais. html . acesso em 20 abril 2010.
} 
[...] não é ofício de poeta narrar o que aconteceu; é, sim, o de representar o que poderia acontecer, quer dizer: o que é possível segundo a verossimilhança e a necessidade. Com efeito, não diferem o historiador e o poeta por escreverem verso ou prosa (pois que bem poderiam ser postos em verso as obras de Heródoto, e nem por isso deixariam de ser história, se fossem em verso o que eram em prosa) - diferem, sim, em que diz um as coisas que sucederam, e outro as que poderiam suceder. Por isso a poesia é algo de mais filosófico e mais sério do que a história, pois refere aquela principalmente o universal, e esta o particular. $^{25}$.

Seguindo o raciocínio aristotélico, a maneira de divisar o factual do ficcional não exclui a possibilidade da articulação do discurso, tanto no texto ficcional quanto no texto não-ficcional. Assim, as narrativas ficcionais e as narrativas factuais são interpretadas pelo leitor tendo em vista o contexto que essas assumem.

A condição do migrante indicia aspectos paradoxais tanto no âmbito do real quanto do ficcional. Sabe-se que a movimentação, a errância, a migração, o nomadismo não é característica somente deste século, do território brasileiro, da realidade ou da ficção. É um fenômeno que já atravessou os espaços temporais e geográficos ocupados pela humanidade. Isso pode ser constatado tanto na narrativa histórica quanto na narrativa ficcional. Ao que nos parece, nesse caso, observam-se a conveniência do emissor e também a do receptor.

\subsection{Migrantese identidade}

Dentre as diversas migrações, muitos autores assim as conceituam: migração externa, migração interna, êxodo; transumância (ida e volta); migração temporária e migrações diversas (de fim de semana e outras). ${ }^{26}$

Conforme o estudo A celebração do outro na constituição da identidade do brasileiro,

[...] a migração traz conseqüências de rejeição e discriminação e que o imaginário dos habitantes das diferentes regiões do país com relação às demais

\footnotetext{
${ }^{25}$ ARISTÓTELES. Arte poética. Trad. Eudoro de Souza. São Paulo: Ars Poética, 1993, p. 53-54; trata-se do parágrafo 50, que abre o capítulo IX. (Ed. bilíngue, coleção Ensaio, série Clássica, v. 1).

${ }^{26} \mathrm{~A}$ informação é tão disseminada que se torna ocioso referendá-la com alguma abonação.
} 
funciona de um modo semelhante ao que caracteriza a relação entre os países dos Hemisférios Norte e Sul: o Nordeste para o paulistano é o lugar do repouso, do sonho, da indolência, assim como o Brasil para os europeus; São Paulo para o nordestino é o lugar do trabalho, do futuro, da tecnologia, estereótipos que permanecem na memória discursiva e afloram nas atitudes do dia-a-dia. ${ }^{27}$.

Vale enfatizar que esse é um tema que não deveria ser ignorado pelos pesquisadores que almejam estudar o fenômeno da migração. Da mesma forma, não se devem deixar para um segundo plano as produções literárias que abordam tais questões.

Se para a historiografia o migrante é um ser provisório, outsider ou designação outra; em muitas obras de ficção, o migrante é, simultaneamente, o marginalizado, o excluído, o outro ampliado, hibridizado, livre e prisioneiro, herói e anti-herói que, às vezes, consegue vencer as adversidades, encenando diversas máscaras e pertencimentos.

Nesse sentido, a obra Vidas Secas, de Graciliano Ramos - narrativa que se define apenas por dois movimentos: o da partida e o da chegada dos migrantes - emerge reflexões significativas acerca das migrações internas e estigmatização social do ser migrante.

Entretanto, somente uma leitura atenta desses gêneros textuais levará o pesquisador a não se enredar nos discursos do senso comum quanto ao assunto.

Nos dizeres de Elias e Scotson ${ }^{28}$ :

Atualmente, há tendência a discutir o problema da estigmatização social como se ele fosse uma simples questão de pessoas que demonstram, individualmente, um desapreço acentuado por outras pessoas como indivíduos. Um modo conhecido de conceituar esse tipo de observação é classificá-la como preconceito. Entretanto, isso equivale a discernir apenas no plano individual algo que não pode ser entendido sem que se o perceba, ao mesmo tempo, no nível do grupo (...). Portanto, perde-se a chave do problema que costuma ser discutido em categorias com a de "preconceito social" quando ela é exclusivamente bus-

${ }^{27}$ COSTA, Ana. A celebração do outro na constituição da identidade do brasileiro. In: CORACINI, Maria José. A celebração do outro: arquivo, memória e identidade: línguas (materna e estrangeira), plurilinguismo e tradução. Campinas: Mercado das Letras, 2007, p. 74.

${ }^{28}$ NORBET, Elias, SCOTSON, J. L. Os estabelecimentos e os outsiders: sociologia das relações de poder a partir de uma pequena comunidade. Rio de Janeiro: Jorge Zahar, 2000, p. 23. 
cada na estrutura de personalidade dos indivíduos. Ela só pode ser encontrada ao se considerar a figuração formada pelos dois (ou mais) grupos implicados ou, em outras palavras, a natureza de sua interdependência.

E, ainda, conforme afirma Stuart Hall, "[...] a identidade está profundamente envolvida no processo de representação" ${ }^{29}$. Nesse sentido, o tempo e o espaço simbólicos são também diretrizes fundamentais para a representação, para a recriação poética do migrante, do ex-ótico.

Para homologar nossas considerações, nos dizeres de Oliveira ${ }^{30}$ :"Os outros [...] eram e são vistos como exóticos também em seu sentido original: ex-ótico, ou seja, fora do lugar comum da visão, estranho. Os que não eram e não são europeus, mas, fundamentalmente, como seres e lugares a serem apossados por esses valores e essas fronteiras." ( grifo do autor).

Apresentar e discutir os diferentes significados que o migrante assume no pensamento social, pode indiciar diversos caminhos para novas reflexões acerca das mobilizações que ocorreram no passado e ainda prosseguem no presente. A conquista e a ocupação de terras oferecem uma abrangente retomada na construção da identidade - ou das identidades.

\section{Conclusão}

A migração é fenômeno global e, desde a Antiguidade, a presença do migrante traz ecos de sentimentos, (in) diferenças, pertença e pertencer. Há muito, o migrante assume um papel de pioneiro: encontra e amplia novas terras, novas formas de cultura, crenças, linguísticas e saberes. Paradoxalmente, mesmo com essa dinâmica, os migrantes são vistos de formas diversas pelas localidades receptoras, sendo considerados vilóes ou heróis, de acordo com os interesses dos grupos dominantes.

Observamos que, de acordo com a necessidade e interesse dos grupos dominantes, cria-se sempre um jeito próprio de relacionar com o migrante. Assim foi com a história da migração brasileira, com a homologação da Constituição

\footnotetext{
${ }^{29}$ HALL, Stuart. Op. cit., p. 61.

${ }^{30}$ OLIVEIRA, Marco A. M. Op. cit., p. 82.
} 
de 1824 e, parece, não ter mudado tanto. Até quando tal fato será ignorado por certos estudiosos?

Desse modo, constatamos que estudar migrações e migrantes não se limita à verificação de um deslocamento populacional de um local para outro. Em torno desse processo está contida uma série de fatores, também subjetivos: alegrias, dores, saudades, esperanças, ilusões, encantamentos e sonhos. Assim, faz-se necessária uma nova forma de discussão acerca de migrações e migrantes, visando a novas pesquisas a fim de que se "quebrem" paradigmas e conceitos que, em muitos dos casos, estão cristalizados.

Corroboram nosso raciocínio, os dizeres de Oliveira ${ }^{31}$ : “[...] Assim, o imigrante foi quem pensou, agiu ou não, antes do pesquisador que se encontra diante daquilo ou daquele que esta sendo analisado. [...] o que o imigrante mais quer é ser representado, espelhado em uma história que também é sua, identificado na imagem analisada e construída pelo investigador."

Desse modo, para nosso ponto de vista, talvez seja adequado ratificar que, nesse percurso de leitura, as reflexões apresentadas não se configuram como únicas e findas, já que não almejamos exaurir tal assunto neste estudo. Contudo, com esta leitura empírico-reflexiva, constatamos que, enquanto produto humano, a Literatura em interface com a História apresenta-se como importante elemento para os Estudos Fronteiriços ao que se refere a migrantes e migrações. Na obra literária de ficção, à medida que o emissor "dá vida" às personagens, ele vai desvelando aspectos que a historiografia não registrou, por conveniência, ou porque os quis ignorar.

Miroslav Milovic, na obra Comunidade da diferença, atenta para o seguinte: "Pensar o ser é uma questão antiga. Agora se deve pensá-lo como algo objetivo à nossa subjetividade?"32.

Com isso, buscar um novo olhar para essas determinações nos remete a novas possibilidades de conhecimento. Paradigmas, hipóteses e resultados cristali-

\footnotetext{
${ }^{31}$ OLIVEIRA, Marco A. M. O imigrante: a fronteira feito homem?. In: Revista Arte \& Ciência, n. 10, abril 2009, p. 4. Disponível em http://www.arteciencia.com. Acesso em 14 maio 2008.

${ }^{32}$ MILOVIC, Mirolav. Comunidade da diferença. Rio de Janeiro: Relume Dumará; Ijuí, RS: Unijuí, 2004, p. 47.
} 
zados, e até mesmo o rigor científico podem nos levar ao encontro de armadilhas que inibem e retardam novas interpretações e $\operatorname{conceitos}^{33}$.

Ao bebermos de vários estudos publicados acerca de migrantes e migrações e, em especial, ao lermos o conjunto da obra do poeta Manoel de Barros, bem como as dos ficcionistas brasileiros que abordam o tema citado neste estudo, constatamos que, no ponto em que convergem os dois tipos de discurso - o científico e o literário - , se por um lado a Literatura brasileira há muito tem desvelado a migração, em seus diversos aspectos, por outro, a historiografia brasileira, somente no último século, apresenta uma abordagem um tanto desvinculada da visão política imposta às movimentações populacionais.

Entendemos que a conjuntura político-econômico-social de cada época influencia os fluxos migratórios, ora em maior, ora em menor intensidade, visando a interesses, muitas das vezes, alheios aos dos migrantes.

O estudo desse tema remete a um caminho desafiador, para o qual necessitamos de muito mais fôlego e mais conhecimento. Isso nos instiga a novos trabalhos acerca de migrantes e migrações: do factual ao ficcional.

\footnotetext{
${ }^{33}$ OLIVEIRA, Marco A. M. Os imigrantes..., op. cit.
} 